\title{
Genomic overview of protein kinases ${ }^{*}$
}

\author{
Gerard Manning $^{\S}$, Razavi-Newman Center for Bioinformatics, Salk \\ Institute for Biological Studies, La Jolla, California 92037 USA
}

\section{Table of Contents}

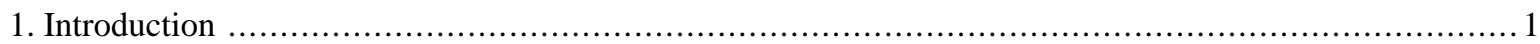

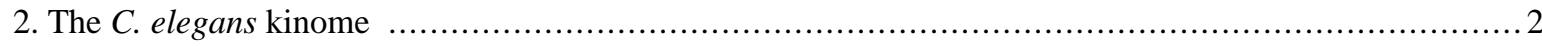

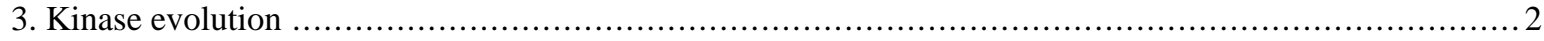

4. Recent expansions and inventions in the worm kinome ................................................

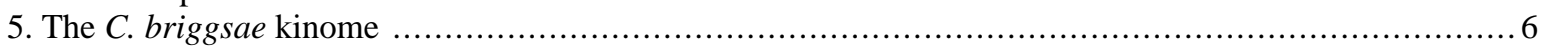

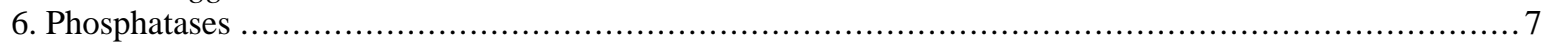

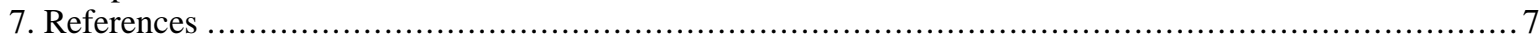

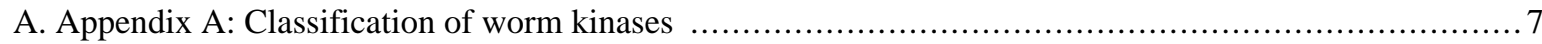

\begin{abstract}
Protein kinases are one of the largest and most influential of gene families: constituting some $2 \%$ of the proteome, they regulate almost all biochemical pathways and may phosphorylate up to $30 \%$ of the proteome. Bioinformatics and comparative genomics were used to determine the $C$. elegans kinome and put it in evolutionary and functional context. Kinases are deeply conserved in evolution, and the worm has family homologs for over $80 \%$ of the human kinome. Almost half of the 438 worm kinases are members of worm-specific or worm-expanded families. Such radiations include genes involved in spermatogenesis, chemosensation, Wnt signaling and FGF receptor-like kinases. The $C$. briggsae kinome is largely similar apart from the expanded classes, showing that such expansions are evolutionarily recent.
\end{abstract}

\section{Introduction}

Protein kinases constitute one of the largest and most important of protein families, accounting for $\sim 2 \%$ of genes in a variety of eukaryotic genomes. By phosphorylating substrate proteins, kinases modify the activity, location and affinities of up to $30 \%$ of all cellular proteins, and direct most cellular processes, particularly in signal transduction and co-ordination of complex pathways. Many of these pathways are highly conserved, and 53 distinct kinase functions and subfamilies appear to have been conserved between yeasts, nematodes, insects and vertebrates, with a further 91 subfamilies of kinases being seen throughout metazoan genomes. This makes kinase signaling particularly amenable to comparative studies, and kinase activity a particularly good readout of the physiological state of any cell.

\footnotetext{
*Edited by Iva Greenwald. Last revised December 10, 2005. Published December 13, 2005. This chapter should be cited as: Manning, G. Genomic overview of Protein Kinases (December 13, 2005), WormBook, ed. The C. elegans Research Community, WormBook, doi/10.1895/wormbook.1.60.1, http://www.wormbook.org.

Copyright: (C) 2005 Gerard Manning. This is an open-access article distributed under the terms of the Creative Commons Attribution License, which permits unrestricted use, distribution, and reproduction in any medium, provided the original author and source are credited.

${ }^{\S}$ To whom correspondence should be addressed. E-mail: manning@ salk.edu
} 
This chapter will introduce the diversity of kinases in C. elegans, and compare them to those of fungi and other metazoans, as well as to preliminary results from analysis of the C. briggsae kinome.

\section{The C. elegans kinome}

Most protein kinases share a common ePK (eukaryotic protein kinase) catalytic domain, and can be identified by sequence similarity with Blast or profile hidden Markov models (HMMs). The remaining atypical protein kinases (aPK) belong to several families, some of which have structural, but not sequence similarity to ePKs. We used ePK and aPK HMMs, and Blast/psi-Blast with divergent kinase sequences, to identify protein kinase sequences in $C$. elegans genomic and expressed sequences (Manning et al., 2002; Plowman et al., 1999). We identified 438 protein kinase genes, including 20 atypical kinases, and an additional 25 kinase fragments or pseudogenes. All sequences and supporting data are available at http://kinase.com, and all but 8 sequences are now identical to wormpep (v. 141) sequences.

\section{Kinase evolution}

To put worm kinases into an evolutionary and functional context, we compared them with the distant kinomes of human, fly, and yeast. At these distances, 1:1 orthology is rare, so we classified each kinase into a hierarchy of groups, families, and sometimes subfamilies (Manning et al., 2002a; Manning et al., 2002b). The classification is based on sequence similarity within the kinase domain, the presence of additional domains, known biological functions, and conservation across divergent genomes. Across the four kinomes, there are 10 groups, 143 families and 212 subfamilies. The classification of each worm kinase is given in Appendix A.

Since kinases perform such a variety of distinct basic cellular functions, it is not surprising to see that 53 subfamilies and functions are present in all four kinomes (Figure 1). A further 91 subfamilies were found in all three metazoan kinomes, including the tyrosine kinase (TK) group and the TKL group, which mediate much of the complexity of intercellular signal transduction. The gain and loss of kinase functions and subfamilies in each evolutionary lineage is also seen. In general, the data support the coelomate clade, where insects are more closely related to vertebrates than to nematodes, rather than the ecdysozoa clade, which groups insects and nematodes together.

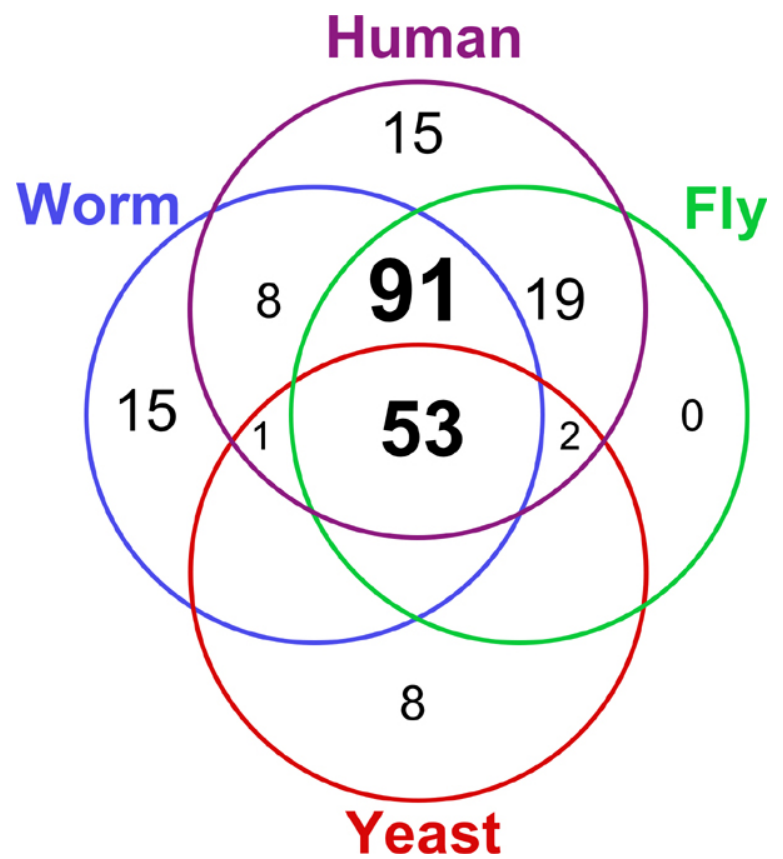

Figure 1. Distribution of 212 kinase subfamilies throughout four kinomes: the yeast Saccharomyces cerevisiae, the nematode worm Caenorhabditis elegans, the fruit fly Drosophila melanogaster and human.

Nematodes share 153 subfamilies with human, providing close homologs for $81 \%$ (419/518) of all human kinases. 6 families appear to have been lost from nematodes, based on their presence in fly, human and more basal 
organisms (Table 1), and several new families have been invented within the coelomate lineage, whose functions predominantly map to immunity/angiogenesis, neurobiology, cell cycle and morphogenesis. There are 13 such human-specific families, and 16 shared between fly and human.

Table 1. Kinases lost in worm, or gained in fly or human kinomes.

\begin{tabular}{|c|c|c|c|c|c|c|}
\hline Group & Family & Subfamily & $\begin{array}{l}\text { Fly } \\
\text { count }\end{array}$ & $\begin{array}{l}\text { Human } \\
\text { count }\end{array}$ & Function & Notes \\
\hline \multicolumn{7}{|c|}{ Secondarily lost from worm } \\
\hline Atypical & G11 & & 1 & 1 & Unknown & Also in yeast and plants \\
\hline CAMK & CAMKL & PASK & 1 & 1 & Glucose sensor & Also in yeast \\
\hline Other & TTK & & 1 & 1 & Cell cycle & Also in yeast and plants \\
\hline Atypical & PIKK & DNAPK & 1 & 1 & DNA repair & Also in Dictyostelium \\
\hline Atypical & TIF & & 1 & 3 & Transcriptional control & $\begin{array}{l}\text { Also in Dictyostelium. NHR } \\
\text { co-factor }\end{array}$ \\
\hline TK & CCK4 & & 1 & 1 & Neuronal; cell growth & $\begin{array}{l}\text { Also in Hydra. Neuronal } \\
\text { pathfinding; cancer }\end{array}$ \\
\hline \multicolumn{7}{|c|}{ Fly + Human } \\
\hline CAMK & Trbl & & 1 & 3 & Cell cycle & \\
\hline CMGC & CDK & CDK10 & 1 & 1 & Cell cycle? & \\
\hline Other & IKK & & 2 & 4 & Immunity & NFkb signaling \\
\hline Other & MOS & & 1 & 1 & Cell cycle & Meiosis \\
\hline Other & SLOB & & 2 & 1 & Neuronal & Synaptic transmission \\
\hline Other & TOPK & & 1 & 1 & Cell cycle & \\
\hline STE & Ste20 & NinaC & 1 & 2 & Neuronal & Phototransduction \\
\hline TK & Jak & & 1 & 4 & Immunity & Cytokine signaling \\
\hline TK & Musk & & 1 & 1 & Neuronal & Synaptic transmission \\
\hline TK & \begin{tabular}{|l} 
PDGFR/ \\
VEGFR
\end{tabular} & & 2 & 8 & $\begin{array}{l}\text { Angiogenesis; } \\
\text { morphogenesis; immunity }\end{array}$ & \\
\hline TK & Ret & & 1 & 1 & Immunity, development & Growth factor receptor \\
\hline TK & Sev & & 1 & 1 & Morphogenesis & \\
\hline TK & Syk & & 1 & 2 & Immunity; morphogenesis & \\
\hline TK & Tec & & 1 & 5 & Immunity; morphogenesis & \\
\hline TKL & LISK & LIMK & 1 & 2 & Cytoskeletal & \\
\hline TKL & LISK & TESK & 1 & 2 & Testis development & \\
\hline \multicolumn{7}{|l|}{ Human } \\
\hline Atypical & Alpha & ChaK & 0 & 2 & Neuronal & $\begin{array}{l}\text { Human adds kinase to } \\
\text { metazoan-wide channel }\end{array}$ \\
\hline Atypical & BCR & & 0 & 1 & Cell growth & $\begin{array}{l}\text { Ras/MAPK growth factor } \\
\text { responses }\end{array}$ \\
\hline Atypical & FAST & & 0 & 1 & Apoptosis & \\
\hline Atypical & H11 & & 0 & 1 & Apoptosis? & \\
\hline CAMK & CAMKL & HUNK & 0 & 1 & Development & Mammary gland development \\
\hline CAMK & Trio & & 0 & 6 & Muscle & $\begin{array}{l}\text { Human adds kinase to } \\
\text { conserved protein }\end{array}$ \\
\hline
\end{tabular}




\begin{tabular}{|l|l|l|l|l|l|l|}
\hline Group & Family & Subfamily & $\begin{array}{l}\text { Fly } \\
\text { count }\end{array}$ & $\begin{array}{l}\text { Human } \\
\text { count }\end{array}$ & Function & Notes \\
\hline Other & NKF3 & & 0 & 2 & Unknown & \\
\hline Other & NKF4 & & 0 & 2 & Cytoskeletal & \\
\hline Other & NKF5 & & 0 & 2 & Testis development? & \\
\hline TK & Axl & & 0 & 3 & Cell growth; adhesion & \\
\hline TK & Lmr & & 0 & 3 & Cell growth? & \\
\hline TK & Tie & & 0 & 2 & Angiogenesis & \\
\hline TKL & RIPK & & 0 & 5 & Immunity & \\
\hline
\end{tabular}

On the other hand, the worm shares eight subfamilies with human which are absent from Drosophila (Table 2). These include two receptor tyrosine kinase families, an atypical elongation factor 2 kinase (eEF2K), several members of the CAMK group (MELK, PSK, PIM) and the HH498 subfamily of Mixed Lineage Kinases (MLK). In some but not all cases, the fly genome has related genes that may fulfill a similar function. SGK, eEF2K and HH498 are found in Dictyostelium, and ABC1-C in yeast, reinforcing their secondary loss from insects. The secondary loss of conserved kinases within each lineage highlights how essential functions are dependent on the context of other genes and pathways in the organism.

Table 2. Kinase subfamilies shared by worm and human, but not fly.

\begin{tabular}{|l|l|l|l|l|l|}
\hline Group & Family & Subfamily & Worm genes & $\begin{array}{l}\text { Human } \\
\text { genes }\end{array}$ & Notes \\
\hline AGC & SGK & & 1 & 3 & Close relative to the AKT (PKB) family \\
\hline Atypical & ABC1 & ABC1-C & 1 & 1 & Other ABC1 subfamilies may compensate. \\
\hline Atypical & MHCK & eEF2K & 1 & 1 & Eukaryotic elongation factor 2 kinase. \\
\hline CAMK & CAMKL & MELK & 1 & 1 & $\begin{array}{l}\text { MELK is an outgroup of MARK, which is } \\
\text { present in fly. Splicing function? }\end{array}$ \\
\hline CAMK & PSK & & 1 & 2 & Human PSKH1 has a Golgi function. \\
\hline CAMK & PIM & & 2 & 3 & $\begin{array}{l}\text { Related to PASK, which is present in fly } \\
\text { and absent from worm. }\end{array}$ \\
\hline TKL & MLK & HH498 & 1 & 1 & $\begin{array}{l}\text { Human form is cardiac-specific, worm is } \\
\text { neuronal- restricted. Divergent functions? }\end{array}$ \\
\hline TK & Trk & & 1 & 3 & $\begin{array}{l}\text { Neurotrophin receptor. Fly has closely } \\
\text { related Ror and Musk families. }\end{array}$ \\
\hline TK & Met & & 2 & 2 & $\begin{array}{l}\text { Worm has a clear Met homolog and a } \\
\text { divergent family member. }\end{array}$ \\
\hline
\end{tabular}

\section{Recent expansions and inventions in the worm kinome}

The $C$. elegans kinome is also marked by a dramatic expansion of a small number of kinase classes. $C$. elegans has almost twice as many kinases as Drosophila (438 vs. 241 genes), but virtually all the difference (195 of 197 genes) is accounted for by expansions of a small number of families and of worm-specific families.

Fifteen kinase subfamilies are nematode-specific, accounting for almost a quarter of the kinome (105 genes). They include 8 distinct subfamilies within a large expansion of CK1 group kinases, containing 78 kinases, and two FGFR-like receptor tyrosine kinase families. An additional 5 families are in the Other group, and have very little similarity to any non-worm kinases. In general, they are not well characterized. 
Table 3. Worm-specific and worm-expanded kinase classes. Counts of genes in kinomes. C. briggsae data from unpublished analysis of genome-predicted peptides.

\begin{tabular}{|l|l|l|l|l|}
\hline Name/Classification & C. elegans & C. briggsae & Fly & Human \\
\hline CK1/Dual & 3 & 3 & 0 & 0 \\
\hline CK1/TTBKL & 31 & 22 & 0 & 0 \\
\hline CK1/Worm6 & 28 & 19 & 0 & 0 \\
\hline CK1/Worm7 & 2 & 1 & 0 & 0 \\
\hline CK1/Worm8 & 3 & 1 & 0 & 0 \\
\hline CK1/Worm9 & 2 & 0 & 0 & 0 \\
\hline CK1/Worm10 & 2 & 2 & 0 & 0 \\
\hline CK1/Worm11 & 1 & 2 & 0 & 0 \\
\hline CK1/Unique & 6 & 3 & 0 & 0 \\
\hline TK/Fer & 38 & 24 & 1 & 2 \\
\hline RGC group & 27 & 20 & 6 & 5 \\
\hline TK/KIN-16 & 16 & 6 & 0 & 0 \\
\hline Other/Haspin & 13 & 1 & 1 & 1 \\
\hline CMGC/GSK3 & 7 & 6 & 3 & 2 \\
\hline CAMK/CAMKL/ CHK1 & 7 & 1 & 1 & 1 \\
\hline Ste/Ste7 & 10 & 8 & 4 & 7 \\
\hline CMGC/MAPK/Jnk & 5 & 3 & 1 & 3 \\
\hline TK/KIN-9 & 5 & 5 & 0 & 0 \\
\hline Other/Worm1 & 2 & 1 & 0 & 0 \\
\hline Other/Worm2 & 3 & 2 & 0 & 0 \\
\hline Other/Worm3 & 2 & 1 & 0 & 0 \\
\hline Other/Worm4 & 1 & 1 & $\mathbf{2 1}$ \\
\hline Other/Worm5 & 3 & 0 & 0 \\
\hline Total & $\mathbf{2 1 7}$ & $\mathbf{1 3 2}$ & 0 \\
\hline & & & 0 \\
\hline
\end{tabular}

These kinases may hold a key to several nematode-specific biological functions. In several cases, the expansions appear recent, as the members are closely related by sequence and chromosomal location, and several appear to have been generated since the $C$. elegans/C. briggsae split. Many may have reduced or no function: several have lost catalytic or other conserved residues and 20 of the 25 worm kinase pseudogenes are from these families, indicating a high rate of gene turnover. A similar expansion is seen in C. briggsae, and though it appears that this is more modest, some of this may be due to the preliminary nature of the annotation and kinase analysis of this genome.

Reproductive functions often drive rapid evolution, and there is some evidence implicating kinase expansions in nematode spermatogeneis. One CK1 gene (spe-6) and one Fer gene (spe-8) function in spermatogenesis, and half or more of these classes are selectively expressed in sperm by microarray analysis (Muhlrad and Ward, 2002; Reinke et al., 2000; P. Muhlrad and S. Ward, pers. commun.).

Receptor guanylate cyclases (RGC) have a catalytically inactive kinase domain, and have separately expanded in all three metazoans, but most dramatically in worm (Morton, 2004). Most are uncharacterized, but several are expressed in highly restricted sets of neurons and are implicated in chemosensation, and one (daf-11) is involved in dauer formation (Vowels and Thomas, 1992). 
The KIN-9 (previously known as kin-6) and KIN-16 families encode receptor tyrosine kinases, whose kinase domains and overall structure most resemble the FGF receptor family. Some of the KIN-16 family have arrays of extracellular immunoglobulin repeats, and some have vestigial extracellular regions (Popovici et al., 1999), while KIN-6 members have diverse novel extracellular regions. KIN-16 includes the old-1 and old-2 genes thought to be involved in age and stress resistance (Rikke et al., 2000). Many of the KIN-16 genes are chromosomally clustered, and are poorly conserved in C. briggsae, indicating a recent origin (Figure 2A). The KIN-9 genes are not clustered and all have briggsae orthologs.

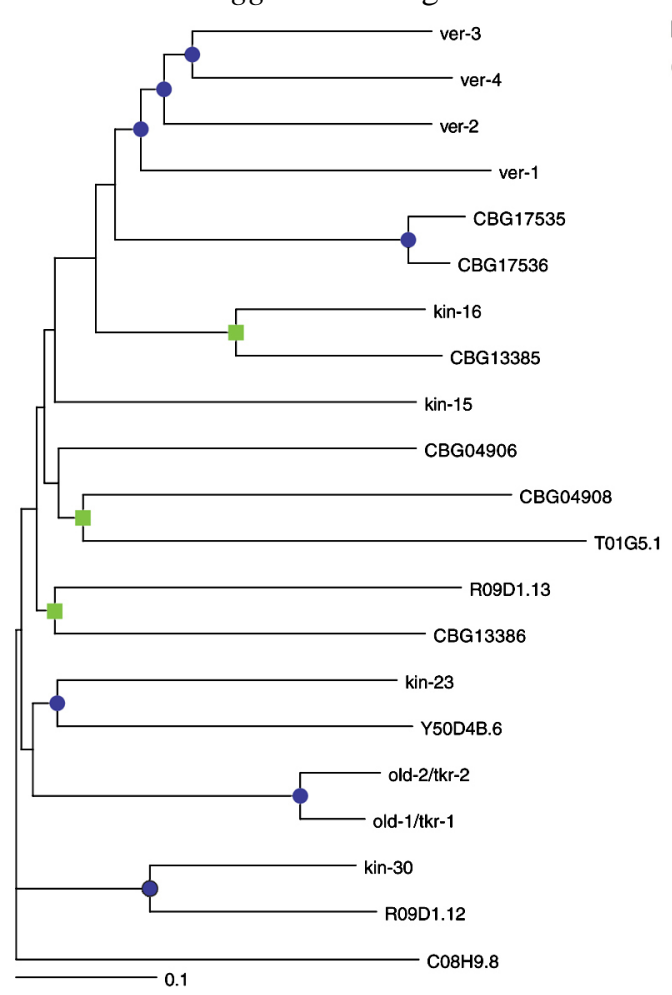

A. Kin-16 family in C. elegans and C. briggsae

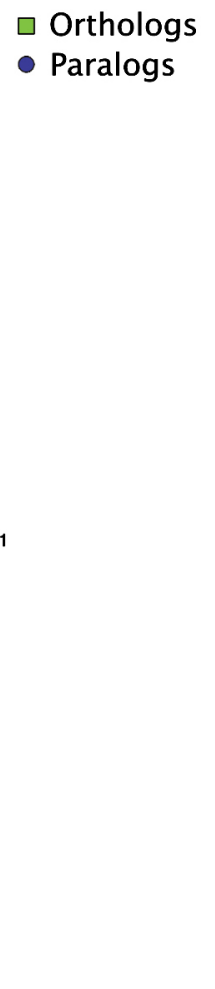

$\square$ Orthologs
- Paralogs

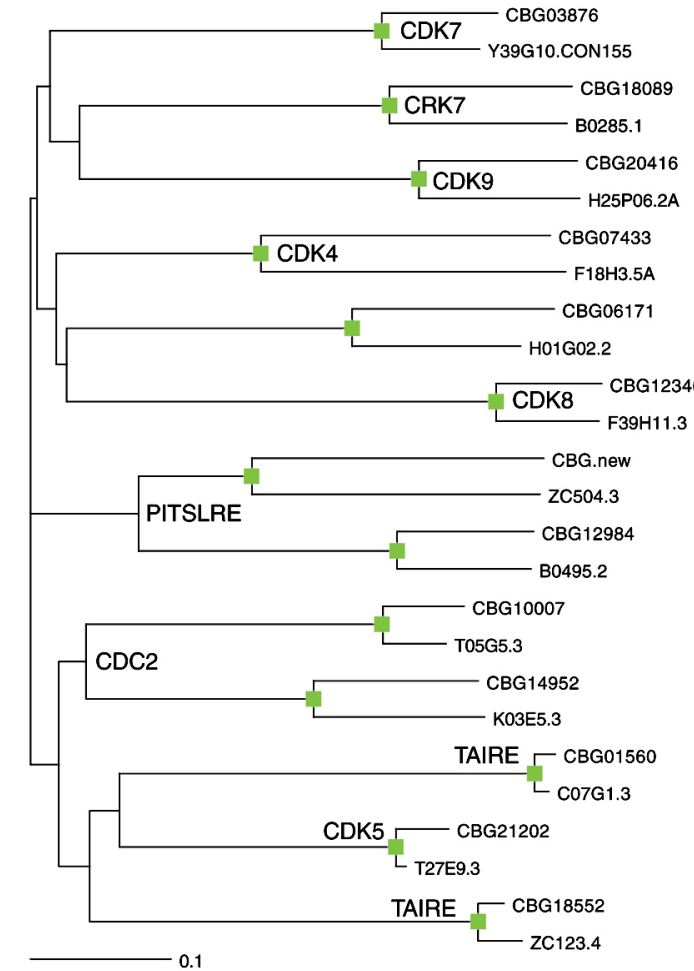

B. CDK family in C. elegans and C. briggsae

Figure 2. Orthology between $C$. elegans and C. briggsae kinases. Squares indicate likely orthologous pairs of kinases, and circles denote paralogous expansions. C. briggsae sequences are predictions (CBGnnnnn) from the genome project. (A) In the worm-specific KIN-16 family, new genes continue to arise in the elegans and briggsae lineages, as indicated by circles. (B) In the CDK family, all 13 members exist as orthologous pairs and subfamilies (labeled) are also conserved in Drosophila and human.

Of the 7 GSK3 members, 6 have clear briggsae homologs, but only one ( $g s k-3)$ has been characterized, and it acts in a defined Wnt signaling pathway (Schlesinger et al., 1999). The additional members may act in an expanded Wnt-like pathway, as worms have other duplicated pathway members including three members each of the beta-catenin and dishevelled families. Both CK1 and Fer kinases are implicated in mammalian Wnt signaling, and some of their worm expansions may also function in this pathway. The role of GSK3 in insulin signaling may also correlate with the expansion of insulin genes in nematodes.

The expansion of the Jnk stress-response MAPK family is partially paralleled by the expansion of the MAPKK (Ste7) family, which now includes 4 putative Jnk kinases (JNKKs).

\section{The C. briggsae kinome}

A preliminary analysis of $C$. briggsae predicted proteins (release 25; Stein et al., 2003) indicates the presence of 341 kinase genes, using the C. elegans kinome as blast query set. An additional 30 or more kinases or kinase fragments were detected by direct search of the genome, but are still poorly predicted. The majority (320) of $C$. briggsae kinases appear orthologous to a single C. elegans kinase, by bidirectional blast searches. The main differences between the two kinomes are in the recently-expanded families, where the expansion appears to have continued since the elegans/briggsae split. Of 21 briggsae-unique kinases, 19 are from expanded families, and 98 of 
117 elegans-unique kinases are from expanded families. More thorough sequence analysis will likely reveal more briggsae kinases and more ortholog pairs, but this data does strongly support both continued gene birth and death, and sequence diversification, within these expanded families. The difference between conserved and expanded families is shown in Figure 2A of the nematode-specific KIN-16 family, in which few pairs of obvious orthologs are seen between the two species. By contrast, the CDK family has 13 members in both species, all of which pair off in an orthologous fashion (Figure 2B).

\section{Phosphatases}

Phosphatases remove phosphates from kinase substrates, both reversing kinase-based activation, and relieving kinase-mediated repressions. Phosphatases belong to several different families, including a number of distinct phosphatase domains: the PTP (protein tyrosine phosphatase), DSP (dual-specificity phosphatase which dephosphorylates both tyrosine and serine/threonine) and several families of STP, or serine-threonine phosphatases. While 'phosphatome' analysis lags behind that of the kinomes, an initial survey of C. elegans phosphatases identified 83 PTPs, 26 DSPs and 65 STPs (Plowman et al., 1999). The completion of two nematode genomes and multiple other eukaryotic genomes now opens the door for comparative analysis to identify additional $C$. elegans phosphatases and to compare their distribution with those of other organisms, and with the expansions of their cognate kinomes.

\section{References}

Manning, G., Plowman, G.D., Hunter, T., and Sudarsanam, S. (2002a). Evolution of protein kinase signaling from yeast to man. Trends Biochem. Sci. 27, 514-520. Abstract Article

Manning, G., Whyte, D.B., Martinez, R., Hunter, T., and Sudarsanam, S. (2002b). The protein kinase complement of the human genome. Science 298, 1912-1934. Abstract Article

Morton, D.B. (2004). Invertebrates yield a plethora of atypical guanylyl cyclases. Mol. Neurobiol. 29, 97-116. Abstract

Muhlrad, P.J., and Ward, S. (2002). Spermiogenesis initiation in Caenorhabditis elegans involves a casein kinase 1 encoded by the spe- 6 gene. Genetics $161,143-1550$. Abstract

Plowman, G.D., Sudarsanam, S., Bingham, J., Whyte, D., and Hunter, T. (1999). The protein kinases of Caenorhabditis elegans: a model for signal transduction in multicellular organisms. Proc. Natl. Acad. Sci. USA 96, 13603-13610. Abstract Article

Popovici, C., Roubin, R., Coulier, F., Pontarotti, P., and Birnbaum, D. (1999). The family ofCaenorhabditis elegans tyrosine kinase receptors: similarities and differences with mammalian receptors. Genome Res. 9, 1026-1039. Abstract

Reinke, V., Smith, H.E., Nance, J., Wang, J., Van Doren, C., Begley, R., Jones, S.J., Davis, E.B., Scherer, S., Ward, S., and Kim, S.K. (2000). A global profile of germline gene expression in C. elegans. Mol. Cell 6, $605-616$. Abstract

Rikke, B.A., Murakami, S., and Johnson, T.E. (2000). Paralogy and orthology of tyrosine kinases that can extend the life span of Caenorhabditis elegans. Mol. Biol. Evol. 17, 671-683. Abstract

Schlesinger, A., Shelton, C.A., Maloof, J.N., Meneghini, M., and Bowerman, B. (1999). Wnt pathway components orient a mitotic spindle in the early Caenorhabditis elegans embryo without requiring gene transcription in the responding cell. Genes Dev. 13, 2028-2038. Abstract

Stein, L.D., Bao, Z., Blasiar, D., Blumenthal, T., Brent, M.R., Chen, N., Chinwalla, A., Clarke, L., Clee, C., Coghlan, A., et al. (2003). The genome sequence of Caenorhabditis briggsae: a platform for comparative genomics. PLoS Biol. 1, E45. Abstract Article

Vowels, J.J., and Thomas, J.H. (1992). Genetic analysis of chemosensory control of dauer formation in Caenorhabditis elegans. Genetics 130, 105-123. Abstract 


\section{A. Appendix A: Classification of worm kinases}

Table 4. Classification of worm kinases

\begin{tabular}{|c|c|c|c|c|c|c|c|}
\hline Group & Family & Subfamily & $\begin{array}{l}\text { \# Kinases } \\
\text { (domains) }\end{array}$ & Distribution & Names & $\begin{array}{l}\text { Other } \\
\text { Wormbook } \\
\text { entries }\end{array}$ & $\begin{array}{l}\text { Name/ function } \\
\text { overview }\end{array}$ \\
\hline $\mathrm{AGC}$ & & & 2 & $\begin{array}{l}\text { Nematodes, } \\
\text { Dictyos- } \\
\text { telium }\end{array}$ & $\begin{array}{l}\text { F31E3.2, } \\
\text { F28C10.3 }\end{array}$ & & \\
\hline $\mathrm{AGC}$ & AKT & & 2 & All kinomes & $a k t-1, a k t-2$ & & PI3K signaling \\
\hline $\mathrm{AGC}$ & DMPK & GEK & 1 & $\begin{array}{l}\text { All } \\
\text { metazoans }\end{array}$ & K08B12.5 & & $\begin{array}{l}\text { Myotonic } \\
\text { dystrophy protein } \\
\text { kinase }\end{array}$ \\
\hline $\mathrm{AGC}$ & DMPK & ROCK & 1 & $\begin{array}{l}\text { Metazoans, } \\
\text { Dictyos- } \\
\text { telium }\end{array}$ & let-502 & & $\begin{array}{l}\text { Myotonic } \\
\text { dystrophy protein } \\
\text { kinase/Rho } \\
\text { kinase }\end{array}$ \\
\hline $\mathrm{AGC}$ & GRK & BARK & 1 & $\begin{array}{l}\text { All } \\
\text { metazoans }\end{array}$ & grk-2 & & $\begin{array}{l}\text { Beta adrenergic } \\
\text { receptor kinase }\end{array}$ \\
\hline $\mathrm{AGC}$ & GRK & GRK & 1 & $\begin{array}{l}\text { All } \\
\text { metazoans }\end{array}$ & grk-1 & & $\begin{array}{l}\text { G protein coupled } \\
\text { kinase }\end{array}$ \\
\hline AGC & MAST & & 1 & $\begin{array}{l}\text { Metazoans, } \\
\text { Dictyos- } \\
\text { telium }\end{array}$ & kin-4 & & $\begin{array}{l}\text { Microtubule } \\
\text { associated serine/ } \\
\text { threonine kinase }\end{array}$ \\
\hline $\mathrm{AGC}$ & NDR & & 2 & All kinomes & sax-1, T20F10.1 & & \\
\hline $\mathrm{AGC}$ & PDK1 & & 2 & All kinomes & $p d k-1, \mathrm{~W} 04 \mathrm{~B} 5.5$ & & PI3K signaling \\
\hline $\mathrm{AGC}$ & PKA & & 2 & All kinomes & kin-1, F47F2.1 & & $\begin{array}{l}\text { cAMP-dependent } \\
\text { protein kinase }\end{array}$ \\
\hline AGC & PKC & Alpha & 1 & $\begin{array}{l}\text { All } \\
\text { metazoans }\end{array}$ & $p k c-2$ & & $\begin{array}{l}\text { Protein kinase } \mathrm{C} \\
\text { isoforms }\end{array}$ \\
\hline $\mathrm{AGC}$ & $\mathrm{PKC}$ & Delta & 1 & $\begin{array}{l}\text { All } \\
\text { metazoans }\end{array}$ & tpa-1 & & $\begin{array}{l}\text { Protein kinase } \mathrm{C} \\
\text { isoforms }\end{array}$ \\
\hline $\mathrm{AGC}$ & PKC & Eta & 1 & $\begin{array}{l}\text { All } \\
\text { metazoans }\end{array}$ & kin-13 & & $\begin{array}{l}\text { Protein kinase } \mathrm{C} \\
\text { isoforms }\end{array}$ \\
\hline $\mathrm{AGC}$ & PKC & Iota & 1 & $\begin{array}{l}\text { All } \\
\text { metazoans }\end{array}$ & $p k c-3$ & & $\begin{array}{l}\text { Protein kinase C } \\
\text { isoforms }\end{array}$ \\
\hline $\mathrm{AGC}$ & $\mathrm{PKG}$ & & 2 & $\begin{array}{l}\text { All } \\
\text { metazoans }\end{array}$ & egl-4, C09G4.2 & & $\begin{array}{l}\text { cGMP-dependent } \\
\text { protein kinase }\end{array}$ \\
\hline $\mathrm{AGC}$ & PKN & & 1 & $\begin{array}{l}\text { All } \\
\text { metazoans }\end{array}$ & F46F6.2 & & Protein kinase $\mathrm{N}$ \\
\hline $\mathrm{AGC}$ & RSK & MSK & 1 & $\begin{array}{l}\text { All } \\
\text { metazoans }\end{array}$ & C54G4.1 & & $\begin{array}{l}\text { Ribosomal S6 } \\
\text { kinase }\end{array}$ \\
\hline $\mathrm{AGC}$ & RSK & $\mathrm{p} 70$ & 2 & $\begin{array}{l}\text { Metazoans, } \\
\text { fungi }\end{array}$ & $\begin{array}{l}\text { Y43D4A.6, } \\
\text { R04A9.5 }\end{array}$ & & $\begin{array}{l}\text { Ribosomal S6 } \\
\text { kinase }\end{array}$ \\
\hline $\mathrm{AGC}$ & RSK & RSK & 1 & $\begin{array}{l}\text { All } \\
\text { metazoans }\end{array}$ & T01H8.1a & & $\begin{array}{l}\text { Ribosomal S6 } \\
\text { kinase }\end{array}$ \\
\hline $\mathrm{AGC}$ & RSKL & & 1 & $\begin{array}{l}\text { All } \\
\text { metazoans }\end{array}$ & F55C5.7 & & $\begin{array}{l}\text { Ribosomal S6 } \\
\text { kinase-like }\end{array}$ \\
\hline $\mathrm{AGC}$ & SGK & & 1 & Nematodes, & W10G6.2 & & Serum/glucocor- \\
\hline
\end{tabular}




\begin{tabular}{|c|c|c|c|c|c|c|c|}
\hline Group & Family & Subfamily & $\begin{array}{l}\text { \# Kinases } \\
\text { (domains) }\end{array}$ & Distribution & Names & $\begin{array}{l}\text { Other } \\
\text { Wormbook } \\
\text { entries }\end{array}$ & $\begin{array}{l}\text { Name/ function } \\
\text { overview }\end{array}$ \\
\hline & & & & $\begin{array}{l}\text { vertebrates, } \\
\text { dictyos- } \\
\text { telium }\end{array}$ & & & $\begin{array}{l}\text { ticoid-regulated } \\
\text { kinase }\end{array}$ \\
\hline AGC & YANK & & 1 & $\begin{array}{l}\text { All } \\
\text { metazoans }\end{array}$ & M03C11.1 & & Uncharacterized \\
\hline Atypical & A6 & & 2 & All kinomes & unc-60, F38E9.5 & & \\
\hline Atypical & $\mathrm{ABC} 1$ & ABC1-A & 1 & All kinomes & C35D10.4 & & \\
\hline Atypical & $\mathrm{ABC} 1$ & ABC1-B & 1 & All kinomes & D2023.6 & & \\
\hline Atypical & $\mathrm{ABC} 1$ & $\mathrm{ABC} 1-\mathrm{C}$ & 1 & $\begin{array}{l}\text { All but } \\
\text { insects }\end{array}$ & Y32H12A.7 & & \\
\hline Atypical & Alpha & eEF2K & 1 & $\begin{array}{l}\text { Nematodes, } \\
\text { vertebrates, } \\
\text { dictyos- } \\
\text { telium }\end{array}$ & efk-1 & & $\begin{array}{l}\text { Elongation factor } \\
2 \text { kinase }\end{array}$ \\
\hline Atypical & BRD & & 3 & $\begin{array}{l}\text { Metazoans, } \\
\text { Dictyos- } \\
\text { telium }\end{array}$ & $\begin{array}{l}\text { Y119C1B.8, } \\
\text { F57C7.1b, } \\
\text { F13C5.2 }\end{array}$ & & $\begin{array}{l}\text { Bromodo-main- } \\
\text { containing kinase }\end{array}$ \\
\hline Atypical & PDHK & & 2 & $\begin{array}{l}\text { Metazoans, } \\
\text { fungi }\end{array}$ & $\begin{array}{l}\text { ZK370.5, } \\
\text { aSWK467 }\end{array}$ & & $\begin{array}{l}\text { Pyruvate } \\
\text { dehydrogenase } \\
\text { kinase }\end{array}$ \\
\hline Atypical & PIKK & ATM & 1 & $\begin{array}{l}\text { Metazoans, } \\
\text { fungi }\end{array}$ & atm-1 & & $\begin{array}{l}\text { DNA damage } \\
\text { response }\end{array}$ \\
\hline Atypical & PIKK & ATR & 1 & All kinomes & atl-1 & & $\begin{array}{l}\text { DNA damage } \\
\text { response }\end{array}$ \\
\hline Atypical & PIKK & FRAP & 1 & All kinomes & B0261.2 & & $\begin{array}{l}\text { Metabolic } \\
\text { regulation (aka } \\
\text { TOR) }\end{array}$ \\
\hline Atypical & PIKK & SMG1 & 1 & $\begin{array}{l}\text { Metazoans, } \\
\text { Dictyos- } \\
\text { telium }\end{array}$ & smg-1 & & $\begin{array}{l}\text { mRNA } \\
\text { surveillance }\end{array}$ \\
\hline Atypical & PIKK & TRRAP & 1 & All kinomes & C47D12.1 & & \\
\hline Atypical & RIO & RIO1 & 1 & All kinomes & M01B12.5 & & \\
\hline Atypical & RIO & RIO2 & 1 & All kinomes & Y105E8B.3 & & \\
\hline Atypical & RIO & RIO3 & 1 & $\begin{array}{l}\text { All } \\
\text { metazoans }\end{array}$ & ZK632.3 & & \\
\hline Atypical & TAF1 & & 1 & All kinomes & taf-1 & & $\begin{array}{l}\text { Basal } \\
\text { transcription: } \\
\text { TFIID associated } \\
\text { factor. }\end{array}$ \\
\hline CAMK & CAMK1 & & 1 & All kinomes & cmk-1 & & $\begin{array}{l}\text { Calmodulin- } \\
\text { dependent protein } \\
\text { kinase 1 }\end{array}$ \\
\hline CAMK & CAMK2 & & 1 & $\begin{array}{l}\text { All } \\
\text { metazoans }\end{array}$ & unc-43 & & $\begin{array}{l}\text { Calmodulin- } \\
\text { dependent protein } \\
\text { kinase 1 }\end{array}$ \\
\hline CAMK & CAMKL & AMPK & 2 & All kinomes & aak-1, aak-2 & & $\begin{array}{l}\text { Metabolic } \\
\text { regulation }\end{array}$ \\
\hline
\end{tabular}




\begin{tabular}{|c|c|c|c|c|c|c|c|}
\hline Group & Family & Subfamily & $\begin{array}{l}\text { \# Kinases } \\
\text { (domains) }\end{array}$ & Distribution & Names & $\begin{array}{l}\text { Other } \\
\text { Wormbook } \\
\text { entries }\end{array}$ & $\begin{array}{l}\text { Name/ function } \\
\text { overview }\end{array}$ \\
\hline CAMK & CAMKL & BRSK & 1 & $\begin{array}{l}\text { Metazoans, } \\
\text { Dictyos- } \\
\text { telium }\end{array}$ & sad-1 & & $\begin{array}{l}\text { Neuronal vesicle } \\
\text { release }\end{array}$ \\
\hline CAMK & CAMKL & CHK1 & $5(7)$ & $\begin{array}{l}\text { Metazoans, } \\
\text { fungi }\end{array}$ & $\begin{array}{l}\text { chk-1, } \\
\text { Y43D4A.6, } \\
\text { R02C2.1, } \\
\text { R02C2.2, DC2.7 }\end{array}$ & & $\begin{array}{l}\text { Cell cycle } \\
\text { checkpoint kinase } \\
1\end{array}$ \\
\hline CAMK & CAMKL & LKB & 1 & $\begin{array}{l}\text { Metazoans, } \\
\text { Dictyos- } \\
\text { telium }\end{array}$ & par-4 & & $\begin{array}{l}\text { Activator of } \\
\text { AMPK }\end{array}$ \\
\hline CAMK & CAMKL & MARK & 2 & All kinomes & par-1, F23C8.8 & \begin{tabular}{|l|} 
Asymmetric \\
cell division \\
and axis \\
formation in the \\
embryo
\end{tabular} & $\begin{array}{l}\text { Microtubule } \\
\text { affinity regulating } \\
\text { kinase }\end{array}$ \\
\hline CAMK & CAMKL & MELK & 1 & $\begin{array}{l}\text { Nematodes } \\
\text { and } \\
\text { vertebrates }\end{array}$ & W03G1.6 & & $\begin{array}{l}\text { Maternal } \\
\text { embryonic } \\
\text { leucine zipper } \\
\text { kinase }\end{array}$ \\
\hline CAMK & CAMKL & NIM1 & 1 & \begin{tabular}{|l|} 
All \\
metazoans
\end{tabular} & F49C5.4 & & \\
\hline CAMK & CAMKL & NuaK & 1 & \begin{tabular}{|l|} 
All \\
metazoans
\end{tabular} & B0496.3 & & Uncharacterized \\
\hline CAMK & CAMKL & QIK & 1 & $\begin{array}{l}\text { Metazoans, } \\
\text { Dictyos- } \\
\text { telium }\end{array}$ & kin-29 & & $\begin{array}{l}\text { Qin induced } \\
\text { kinase }\end{array}$ \\
\hline CAMK & CAMKL & SNRK & 1 & $\begin{array}{l}\text { All } \\
\text { metazoans }\end{array}$ & ZK524.4 & & \\
\hline CAMK & CASK & & 1 & \begin{tabular}{|l|} 
All \\
metazoans
\end{tabular} & lin-2 & & \\
\hline CAMK & DAPK & & 1 & \begin{tabular}{|l|} 
All \\
metazoans
\end{tabular} & K12C11.4 & & $\begin{array}{l}\text { Death-associated } \\
\text { protein kinase }\end{array}$ \\
\hline CAMK & $\begin{array}{l}\text { DCAM- } \\
\text { KL }\end{array}$ & & 2 & \begin{tabular}{|l} 
All \\
metazoans
\end{tabular} & zyg-8, F32D8.1 & & $\begin{array}{l}\text { Doublecortin and } \\
\text { CAMK-like }\end{array}$ \\
\hline CAMK & $\begin{array}{l}\text { MAPK- } \\
\text { APK }\end{array}$ & $\begin{array}{l}\text { MAPK- } \\
\text { APK }\end{array}$ & 2 & \begin{tabular}{|l} 
All \\
metazoans
\end{tabular} & $\begin{array}{l}\text { K08F8.1, } \\
\text { C44C8.6 }\end{array}$ & & $\begin{array}{l}\text { MAPK activated } \\
\text { protein kinase }\end{array}$ \\
\hline CAMK & $\begin{array}{l}\text { MAPK- } \\
\text { APK }\end{array}$ & MNK & 1 & \begin{tabular}{|l|} 
All \\
metazoans
\end{tabular} & R166.5 & & $\begin{array}{l}\text { MAPK activated } \\
\text { protein kinase }\end{array}$ \\
\hline CAMK & MLCK & & $4(5)$ & \begin{tabular}{|l|} 
All \\
metazoans
\end{tabular} & $\begin{array}{l}\text { unc-22, C24G7.5, } \\
\text { ZC373.4, } \\
\text { F12F3.2 }\end{array}$ & & $\begin{array}{l}\text { Myosin light } \\
\text { chain kinase }\end{array}$ \\
\hline CAMK & PHK & & 1 & $\begin{array}{l}\text { All } \\
\text { metazoans }\end{array}$ & Y50D7A.3 & & $\begin{array}{l}\text { Phosphorylase } \\
\text { kinase }\end{array}$ \\
\hline CAMK & PIM & & 2 & $\begin{array}{l}\text { Nematodes } \\
\text { and } \\
\text { vertebrates }\end{array}$ & prk-1,prk-2 & & \\
\hline CAMK & PKD & & 2 & \begin{tabular}{|l|} 
All \\
metazoans
\end{tabular} & $\begin{array}{l}\text { T25E12.4, } \\
\text { W09C5.5 }\end{array}$ & & Protein kinase D \\
\hline
\end{tabular}




\begin{tabular}{|c|c|c|c|c|c|c|c|}
\hline Group & Family & Subfamily & $\begin{array}{l}\text { \# Kinases } \\
\text { (domains) }\end{array}$ & Distribution & Names & \begin{tabular}{|l|} 
Other \\
Wormbook \\
entries
\end{tabular} & $\begin{array}{l}\text { Name/ function } \\
\text { overview }\end{array}$ \\
\hline CAMK & PSK & & 1 & $\begin{array}{l}\text { Nematodes } \\
\text { and } \\
\text { vertebrates }\end{array}$ & R06A10.4 & & $\begin{array}{l}\text { Protein serine } \\
\text { kinase }\end{array}$ \\
\hline CAMK & RAD53 & & 2 & $\begin{array}{l}\text { Metazoans, } \\
\text { fungi }\end{array}$ & chk-2, T08D2.7 & & $\begin{array}{l}\text { DNA damage } \\
\text { checkpoint }\end{array}$ \\
\hline CAMK & $\mathrm{RSKb}$ & $\mathrm{MSKb}$ & $0(1)$ & $\begin{array}{l}\text { All } \\
\text { metazoans }\end{array}$ & C54G4.1 & & $\begin{array}{l}\text { Second domain } \\
\text { of RSK kinases }\end{array}$ \\
\hline CAMK & $\mathrm{RSKb}$ & $\mathrm{RSKb}$ & $0(1)$ & $\begin{array}{l}\text { All } \\
\text { metazoans }\end{array}$ & T01H8.1a & & $\begin{array}{l}\text { Second domain } \\
\text { of RSK kinases }\end{array}$ \\
\hline CAMK & TSSK & & 3 & \begin{tabular}{|l} 
All \\
metazoans
\end{tabular} & $\begin{array}{l}\text { B0511.4, } \\
\text { W02B12.12, } \\
\text { Y38H8A.4 }\end{array}$ & & $\begin{array}{l}\text { Testis-specific } \\
\text { serine kinase }\end{array}$ \\
\hline CK1 & Unique & & 6 & $\begin{array}{l}\text { Some } \\
\text { metazoans }\end{array}$ & $\begin{array}{l}\text { T15B12.2, } \\
\text { ZK507.3, } \\
\text { C25H3.1, } \\
\text { F16B12.5, } \\
\text { ZK507.1, } \\
\text { K09E4.1 }\end{array}$ & & \\
\hline CK1 & CK1 & CK1-A & 1 & $\begin{array}{l}\text { All } \\
\text { metazoans }\end{array}$ & C03C10.1 & & $\begin{array}{l}\text { Cell kinase } \\
\text { 1/Casein kinase } 1\end{array}$ \\
\hline CK1 & CK1 & CK1-D & 1 & All kinomes & $\mathrm{F} 46 \mathrm{~F} 2.2$ & & $\begin{array}{l}\text { Cell kinase } \\
\text { 1/Casein kinase 1 }\end{array}$ \\
\hline CK1 & CK1 & CK1-G & 1 & $\begin{array}{l}\text { Metazoans, } \\
\text { fungi }\end{array}$ & Y106G6E.6 & & $\begin{array}{l}\text { Cell kinase } \\
\text { 1/Casein kinase 1 }\end{array}$ \\
\hline CK1 & Dual & & $3(6)$ & Nematodes & $\begin{array}{l}\text { F59A6.4, } \\
\text { T05A7.6, } \\
\text { H05L14.1 }\end{array}$ & & $\begin{array}{l}\text { Dual-domain } \\
\text { CK1 kinase } \\
\text { subfamily }\end{array}$ \\
\hline CK1 & TTBK & & 1 & \begin{tabular}{|l} 
Metazoans, \\
Dictyos- \\
telium
\end{tabular} & R90.1 & & $\begin{array}{l}\text { Tau tubulin } \\
\text { kinase }\end{array}$ \\
\hline CK1 & TTBKL & & 31 & Nematodes & $\begin{array}{l}\text { M7.7, B0207.7, } \\
\text { F35C11.3, } \\
\text { Y71F9AL.2, } \\
\text { C04G2.2, } \\
\text { C45G9.1, } \\
\text { F32B6.10, } \\
\text { W01B6.2, } \\
\text { C05C12.1, } \\
\text { C49C8.1, } \\
\text { Y73B6A.2, } \\
\text { D2024.1, } \\
\text { Y47G6A.13, } \\
\text { F54H5.2, } \\
\text { C56C10.6, } \\
\text { C53A5.4, } \\
\text { K06H7.8, } \\
\text { D2045.5, } \\
\text { W09C3.1, } \\
\text { R10D12.10, } \\
\text { T11F8.4, } \\
\text { ZC581.2, }\end{array}$ & & $\begin{array}{l}\text { Tau tubulin } \\
\text { kinase-like }\end{array}$ \\
\hline
\end{tabular}




\begin{tabular}{|c|c|c|c|c|c|c|c|}
\hline Group & Family & Subfamily & $\begin{array}{l}\text { \# Kinases } \\
\text { (domains) }\end{array}$ & Distribution & Names & $\begin{array}{l}\text { Other } \\
\text { Wormbook } \\
\text { entries }\end{array}$ & $\begin{array}{l}\text { Name/ function } \\
\text { overview }\end{array}$ \\
\hline & & & & & $\begin{array}{l}\text { T05C12.1, } \\
\text { W06F12.3, } \\
\text { C03C10.2, } \\
\text { T19D12.5, } \\
\text { ZK666.8, } \\
\text { ZK354.6, } \\
\text { F26A1.4, } \\
\text { C14A4.13, } \\
\text { W03G9.5 }\end{array}$ & & \\
\hline CK1 & VRK & & 1 & $\begin{array}{l}\text { All } \\
\text { metazoans }\end{array}$ & F28B12.3 & & $\begin{array}{l}\text { Vaccinia-related } \\
\text { kinase }\end{array}$ \\
\hline CK1 & Worm10 & & 2 & Nematodes & $\begin{array}{l}\text { F26A1.3, } \\
\text { F25F2.1 }\end{array}$ & & Uncharacterized \\
\hline CK1 & Worm11 & & 1 & Nematodes & K11C4.1 & & Uncharacterized \\
\hline CK1 & Worm6 & & 28 & Nematodes & $\begin{array}{l}\text { Y38H8A.3, } \\
\text { C39H7.1, } \\
\text { ZK596.2, } \\
\text { C50F4.10, } \\
\text { C08F8.6, } \\
\text { F36H12.8, } \\
\text { R13H9.5, } \\
\text { Y69F12A.1, } \\
\text { B0218.5, } \\
\text { F36H12.9, } \\
\text { R13H9.6, } \\
\text { T09B4.7, } \\
\text { C09D4.3, } \\
\text { C55B7.10, } \\
\text { F41G3.5, } \\
\text { F38E1.3, } \\
\text { C27D8.1, } \\
\text { Y39G8C.2, } \\
\text { F53C3.1, } \\
\text { F33D11.7, } \\
\text { C34B2.3, } \\
\text { C49C3.2, spe-6, } \\
\text { C09B9.4, } \\
\text { ZK354.2, } \\
\text { Y65B4A.9, } \\
\text { F59E12.3, } \\
\text { C38C3.4 }\end{array}$ & & Uncharacterized \\
\hline CK1 & Worm7 & & 2 & Nematodes & $\begin{array}{l}\text { T01H10.4, } \\
\text { ZC373.3 }\end{array}$ & & Uncharacterized \\
\hline CK1 & Worm8 & & 3 & Nematodes & $\begin{array}{l}\text { F22F1.2, } \\
\text { F39F10.3, } \\
\text { F39F10.2 }\end{array}$ & & Uncharacterized \\
\hline CK1 & Worm9 & & 2 & Nematodes & $\begin{array}{l}\text { K04C1.5, } \\
\text { E02H4.6 }\end{array}$ & & Uncharacterized \\
\hline CMGC & & & 1 & $\begin{array}{l}\text { Nematodes, } \\
\text { fungi }\end{array}$ & F52B5.2 & & \\
\hline CMGC & CDK & & 1 & $\begin{array}{l}\text { Metazoans, } \\
\text { fungi }\end{array}$ & H01G02.2 & & $\begin{array}{l}\text { Cyclin dependent } \\
\text { kinase }\end{array}$ \\
\hline
\end{tabular}




\begin{tabular}{|c|c|c|c|c|c|c|c|}
\hline Group & Family & Subfamily & $\begin{array}{l}\text { \# Kinases } \\
\text { (domains) }\end{array}$ & Distribution & Names & $\begin{array}{l}\text { Other } \\
\text { Wormbook } \\
\text { entries }\end{array}$ & $\begin{array}{l}\text { Name/ function } \\
\text { overview }\end{array}$ \\
\hline CMGC & $\mathrm{CDK}$ & $\mathrm{CDC} 2$ & 2 & All kinomes & $c d k-1, \mathrm{~K} 03 \mathrm{E} 5.3$ & & $\begin{array}{l}\text { Cell cycle: cyclin } \\
\text { dependent kinase }\end{array}$ \\
\hline CMGC & $\mathrm{CDK}$ & CDK4 & 1 & $\begin{array}{l}\text { All } \\
\text { metazoans }\end{array}$ & $c d k-4$ & & $\begin{array}{l}\text { Cell cycle: cyclin } \\
\text { dependent kinase }\end{array}$ \\
\hline CMGC & $\mathrm{CDK}$ & CDK5 & 1 & \begin{tabular}{|l|} 
All \\
metazoans
\end{tabular} & $c d k-5$ & & $\begin{array}{l}\text { Cyclin dependent } \\
\text { kinase }\end{array}$ \\
\hline CMGC & $\mathrm{CDK}$ & CDK7 & 1 & All kinomes & $c d k-7$ & & $\begin{array}{l}\text { Cell cycle: cyclin } \\
\text { dependent kinase }\end{array}$ \\
\hline CMGC & $\mathrm{CDK}$ & CDK8 & 1 & All kinomes & F39H11.3 & & $\begin{array}{l}\text { Cell cycle: cyclin } \\
\text { dependent kinase }\end{array}$ \\
\hline CMGC & $\mathrm{CDK}$ & CDK9 & 1 & $\begin{array}{l}\text { All } \\
\text { metazoans }\end{array}$ & H25P06.2 & & $\begin{array}{l}\text { Cell cycle: cyclin } \\
\text { dependent kinase }\end{array}$ \\
\hline CMGC & $\mathrm{CDK}$ & CRK7 & 1 & All kinomes & B0285.1 & & $\begin{array}{l}\text { Cell cycle: cyclin } \\
\text { dependent kinase }\end{array}$ \\
\hline CMGC & $\mathrm{CDK}$ & PITSLRE & 2 & $\begin{array}{l}\text { Metazoans, } \\
\text { Dictyos- } \\
\text { telium }\end{array}$ & $\begin{array}{l}\text { ZC504.3, } \\
\text { B0495.2 }\end{array}$ & & $\begin{array}{l}\text { Cell cycle: cyclin } \\
\text { dependent kinase }\end{array}$ \\
\hline CMGC & $\mathrm{CDK}$ & TAIRE & 2 & $\begin{array}{l}\text { All } \\
\text { metazoans }\end{array}$ & pct-1, ZC123.4 & & $\begin{array}{l}\text { Cell cycle: cyclin } \\
\text { dependent kinase }\end{array}$ \\
\hline CMGC & CDKL & & 1 & \begin{tabular}{|l|} 
All \\
metazoans
\end{tabular} & Y42A5A.4 & & $\begin{array}{l}\text { Cyclin dependent } \\
\text { kinase-like }\end{array}$ \\
\hline CMGC & CLK & & 3 & All kinomes & $\begin{array}{l}\text { C16A11.3, } \\
\text { Y111B2A.1, } \\
\text { E02H4.3 }\end{array}$ & & $\begin{array}{l}\text { CDC-like kinase, } \\
\text { involved in } \\
\text { splicing }\end{array}$ \\
\hline CMGC & Dyrk & Dyrk1 & 1 & \begin{tabular}{|l} 
Metazoans, \\
Dictyos- \\
telium
\end{tabular} & $m b k-1$ & & \\
\hline CMGC & Dyrk & Dyrk2 & 3 & $\begin{array}{l}\text { Metazoans, } \\
\text { Dictyos- } \\
\text { telium }\end{array}$ & $\begin{array}{l}m b k-2, \text { C36B7.1, } \\
\text { C36B7.2 }\end{array}$ & & \\
\hline CMGC & Dyrk & HIPK & 1 & $\begin{array}{l}\text { All } \\
\text { metazoans }\end{array}$ & $h p k-1$ & & $\begin{array}{l}\text { Hypoxia-induc- } \\
\text { ible protein } \\
\text { kinase }\end{array}$ \\
\hline CMGC & Dyrk & PRP4 & 1 & $\begin{array}{l}\text { Metazoans, } \\
\text { Dictyos- } \\
\text { telium }\end{array}$ & F22D6.5 & & $\begin{array}{l}\text { mRNA } \\
\text { processing }\end{array}$ \\
\hline CMGC & GSK & & 7 & All kinomes & $\begin{array}{l}\text { gsk-3, R03D7.5, } \\
\text { Y106G6D.4, } \\
\text { C44H4.6, } \\
\text { Y106G6E.1, } \\
\text { C36B1.10, } \\
\text { F21F3.2 }\end{array}$ & & $\begin{array}{l}\text { Glycogen } \\
\text { synthase kinase } 3\end{array}$ \\
\hline CMGC & MAPK & & 3 & $\begin{array}{l}\text { Some } \\
\text { metazoans }\end{array}$ & $\begin{array}{l}\text { W06B3.2, } \\
\text { F09C12.2, } \\
\text { C04G6.1 }\end{array}$ & & \\
\hline CMGC & MAPK & Erk & 1 & All kinomes & $m p k-1$ & $\begin{array}{l}\text { RTKRas/ MAP } \\
\text { kinase signaling }\end{array}$ & $\begin{array}{l}\text { Growth factor } \\
\text { response MAPK }\end{array}$ \\
\hline CMGC & MAPK & Erk7 & 1 & Metazoans, & C05D10.2 & & Variant MAPK \\
\hline
\end{tabular}




\begin{tabular}{|c|c|c|c|c|c|c|c|}
\hline Group & Family & Subfamily & $\begin{array}{l}\text { \# Kinases } \\
\text { (domains) }\end{array}$ & Distribution & Names & $\begin{array}{l}\text { Other } \\
\text { Wormbook } \\
\text { entries }\end{array}$ & $\begin{array}{l}\text { Name/ function } \\
\text { overview }\end{array}$ \\
\hline & & & & \begin{tabular}{|l} 
Dictyos- \\
telium
\end{tabular} & & & \\
\hline CMGC & MAPK & Jnk & 5 & $\begin{array}{l}\text { All } \\
\text { metazoans }\end{array}$ & $\begin{array}{l}\text { jnk-1, T07A9.3, } \\
\text { Y51B9A.9, } \\
\text { ZC416.4, } \\
\text { C49C3.10 }\end{array}$ & $\begin{array}{l}\text { Signaling in the } \\
\text { immune } \\
\text { response }\end{array}$ & $\begin{array}{l}\text { Stress-response } \\
\text { MAPK }\end{array}$ \\
\hline CMGC & MAPK & nmo & 1 & $\begin{array}{l}\text { All } \\
\text { metazoans }\end{array}$ & lit-1 & & Variant MAPK \\
\hline CMGC & MAPK & p38 & 3 & $\begin{array}{l}\text { Metazoans, } \\
\text { fungi }\end{array}$ & $\begin{array}{l}\text { pmk-1, pmk-2, } \\
\text { pmk-3 }\end{array}$ & & $\begin{array}{l}\text { Stress-response } \\
\text { MAPK }\end{array}$ \\
\hline CMGC & RCK & & 1 & All kinomes & M04C9.5 & & \\
\hline CMGC & SRPK & & 1 & All kinomes & spk-1 & & mRNA splicing \\
\hline Other & Unique & & 10 & All kinomes & $\begin{array}{l}f l r-4, z y g-1, \\
\text { Y106G6A.1, } \\
\text { D2045.7, } \\
\text { K09A9.1, } \\
\text { Y53F4B.1, } \\
\text { K11H12.9, } \\
\text { K02E10.7, } \\
\text { F37E3.3, } \\
\text { C29H12.5 }\end{array}$ & & \\
\hline Other & Aur & & 2 & All kinomes & air-1, air-2 & & $\begin{array}{l}\text { Cell cycle/chrom- } \\
\text { osomal stability }\end{array}$ \\
\hline Other & Bub & & 1 & All kinomes & $b u b-1$ & & Cell cycle \\
\hline Other & Bud32 & & 1 & All kinomes & F52C12.2 & & $\begin{array}{l}\text { Essential } \\
\text { homolog of yeast } \\
\text { Bud32. }\end{array}$ \\
\hline Other & CAMKK & Meta & 1 & \begin{tabular}{|l} 
Metazoans, \\
Dictyos- \\
telium
\end{tabular} & $c k k-1$ & & CAMK kinase \\
\hline Other & CDC7 & & 1 & All kinomes & C34G6.5 & & $\begin{array}{l}\text { Variant cyclin- } \\
\text { dependent kinase }\end{array}$ \\
\hline Other & CK2 & & 1 & All kinomes & B0205.7 & & $\begin{array}{l}\text { Cell kinase } \\
\text { 2/Casein kinase } 2\end{array}$ \\
\hline Other & Haspin & & 13 & All kinomes & $\begin{array}{l}\text { Y18H1A.10, } \\
\text { K08B4.5, } \\
\text { C50H2.7, } \\
\text { T05E8.2, } \\
\text { ZK177.2, } \\
\text { H12I13.1, } \\
\text { Y48B6A.10, } \\
\text { C01H6.9, } \\
\text { F22H10.5, } \\
\text { C04G2.10, } \\
\text { Y40A1A.1, } \\
\text { Y73B6A.1, } \\
\text { aSWK457 }\end{array}$ & & $\begin{array}{l}\text { Nuclear kinase; } \\
\text { meiosis? }\end{array}$ \\
\hline Other & IRE & & 1 & All kinomes & ire-1 & & $\begin{array}{l}\text { Unfolded protein } \\
\text { response }\end{array}$ \\
\hline
\end{tabular}




\begin{tabular}{|c|c|c|c|c|c|c|c|}
\hline Group & Family & Subfamily & $\begin{array}{l}\text { \# Kinases } \\
\text { (domains) }\end{array}$ & Distribution & Names & $\begin{array}{l}\text { Other } \\
\text { Wormbook } \\
\text { entries }\end{array}$ & $\begin{array}{l}\text { Name/ function } \\
\text { overview }\end{array}$ \\
\hline Other & Nak & & 2 & All kinomes & sel-5, F46G11.3 & & \\
\hline Other & Nek & & 4 & All kinomes & $\begin{array}{l}\text { F19H6.1, } \\
\text { ZC581.1, } \\
\text { Y39G10AR.3, } \\
\text { pqn-25, }\end{array}$ & & $\begin{array}{l}\text { Cell cycle } \\
\text { (NIMA-related } \\
\text { kinase) }\end{array}$ \\
\hline Other & NKF1 & & 1 & $\begin{array}{l}\text { All } \\
\text { metazoans }\end{array}$ & C01C4.3 & & Uncharacterized \\
\hline Other & NKF2 & & 1 & \begin{tabular}{|l} 
All \\
metazoans
\end{tabular} & EEED8.9 & & Uncharacterized \\
\hline Other & NRBP & & 1 & $\begin{array}{l}\text { All } \\
\text { metazoans }\end{array}$ & K10D3.5 & & $\begin{array}{l}\text { Nuclear receptor } \\
\text { binding protein }\end{array}$ \\
\hline Other & PEK & GCN2 & 1 & All kinomes & Y81G3A.3 & & \\
\hline Other & PEK & PEK & 2 & \begin{tabular}{|l} 
Metazoans, \\
Dictyos- \\
telium
\end{tabular} & $\begin{array}{l}\text { pek-1, } \\
\text { Y38E10A.8 }\end{array}$ & & \\
\hline Other & PLK & & 3 & All kinomes & $\begin{array}{l}\text { plk-1, plk-2, } \\
\text { F55G1.8 }\end{array}$ & & $\begin{array}{l}\text { Cell cycle: } \\
\text { polo-like kinase }\end{array}$ \\
\hline Other & SCY1 & & 2 & All kinomes & $\begin{array}{l}\text { W07G4.3, } \\
\text { ZC581.9 }\end{array}$ & & \\
\hline Other & TBCK & & 1 & $\begin{array}{l}\text { Metazoans, } \\
\text { Dictyos- } \\
\text { telium }\end{array}$ & C33F10.2 & & $\begin{array}{l}\text { TBC domain } \\
\text { kinase }\end{array}$ \\
\hline Other & TLK & & 1 & $\begin{array}{l}\text { All } \\
\text { metazoans }\end{array}$ & C07A9.3 & & $\begin{array}{l}\text { Tousled-like } \\
\text { kinase }\end{array}$ \\
\hline Other & ULK & & 2 & All kinomes & unc-51, T07F12.4 & & $\begin{array}{l}\text { Homolog of } \\
\text { Drosophila Fused }\end{array}$ \\
\hline Other & VPS15 & & 1 & All kinomes & ZK930.1 & & \\
\hline Other & WEE & & 2 & All kinomes & wee-1.1, wee-1.3 & & Cell cycle \\
\hline Other & Wnk & & 1 & $\begin{array}{l}\text { All } \\
\text { metazoans }\end{array}$ & C46C2.1 & & $\begin{array}{l}\text { With no } \\
\text { lysine[K] }\end{array}$ \\
\hline Other & Worm1 & & 2 & Nematodes & mes-1, B0198.3 & & Uncharacterized \\
\hline Other & Worm2 & & 3 & Nematodes & $\begin{array}{l}\text { K09C6.8, } \\
\text { T10B5.2, } \\
\text { K09C6.7 }\end{array}$ & & Uncharacterized \\
\hline Other & Worm3 & & 2 & Nematodes & $\begin{array}{l}\text { R107.4, } \\
\text { Y39G8B.5 }\end{array}$ & & Uncharacterized \\
\hline Other & Worm4 & & 1 & Nematodes & C28A5.6 & & Uncharacterized \\
\hline Other & Worm5 & & 3 & Nematodes & $\begin{array}{l}\text { C44C10.7, } \\
\text { F16B12.7, } \\
\text { K08H2.5 }\end{array}$ & & Uncharacterized \\
\hline RGC & RGC & & 27 & $\begin{array}{l}\text { All } \\
\text { metazoans }\end{array}$ & $\begin{array}{l}\text { gcy-13, gcy-14, } \\
\text { odr-1, gcy-19, } \\
\text { gcy-15, gcy-9, } \\
\text { daf-11, } \\
\text { T01A4.1b, gcy-4, } \\
\text { gcy-17, gcy-3, } \\
\text { gcy-7, C04H5.4a, }\end{array}$ & & $\begin{array}{l}\text { Receptor } \\
\text { guanylate cyclase }\end{array}$ \\
\hline
\end{tabular}




\begin{tabular}{|c|c|c|c|c|c|c|c|}
\hline Group & Family & Subfamily & $\begin{array}{l}\text { \# Kinases } \\
\text { (domains) }\end{array}$ & Distribution & Names & $\begin{array}{l}\text { Other } \\
\text { Wormbook } \\
\text { entries }\end{array}$ & $\begin{array}{l}\text { Name/ function } \\
\text { overview }\end{array}$ \\
\hline & & & & & $\begin{array}{l}\text { gcy-11, gcy-18, } \\
\text { gcy-25, gcy-21, } \\
\text { gcy-27, gcy-23, } \\
\text { gcy-1, gcy-20, } \\
\text { gcy-5, gcy-6, } \\
\text { gcy-8, gcy-22, } \\
\text { gcy-2, gcy- } 12\end{array}$ & & \\
\hline STE & Unique & & 1 & \begin{tabular}{|l|} 
Metazoans, \\
Dictyos- \\
telium
\end{tabular} & F18F11.4 & & \\
\hline STE & Ste11 & & 2 & All kinomes & $n s y-1, \mathrm{~B} 0414.7$ & & $\begin{array}{l}\text { MAP kinase } \\
\text { kinase kinase }\end{array}$ \\
\hline STE & Ste20 & FRAY & 1 & $\begin{array}{l}\text { Metazoans, } \\
\text { Dictyos- } \\
\text { telium }\end{array}$ & Y59A8B.23 & & $\begin{array}{l}\text { MAP4 kinase and } \\
\text { related }\end{array}$ \\
\hline $\begin{array}{l}\text { STE } \\
\text { ST }\end{array}$ & Ste20 & KHS & 1 & $\begin{array}{l}\text { All } \\
\text { metazoans }\end{array}$ & ZC404.9 & & $\begin{array}{l}\text { Subfamily of } \\
\text { MAP4K kinases }\end{array}$ \\
\hline STE & Ste20 & MSN & 1 & $\begin{array}{l}\text { All } \\
\text { metazoans }\end{array}$ & ZC504.4 & & $\begin{array}{l}\text { Subfamily of } \\
\text { MAP4K kinases }\end{array}$ \\
\hline STE & Ste20 & MST & 1 & All kinomes & F14H12.4 & & $\begin{array}{l}\text { Subfamily of } \\
\text { MAP4K kinases }\end{array}$ \\
\hline STE & Ste20 & PAKA & 2 & All kinomes & $\begin{array}{l}\text { C09B8.7, } \\
\text { Y38F1A.1 }\end{array}$ & & $\begin{array}{l}\text { Couples small } \\
\text { GTPases to } \\
\text { cytoskeleton }\end{array}$ \\
\hline STE & Ste20 & PAKB & 1 & $\begin{array}{l}\text { All } \\
\text { metazoans }\end{array}$ & C45B11.1 & & $\begin{array}{l}\text { Couples small } \\
\text { GTPases to } \\
\text { cytoskeleton }\end{array}$ \\
\hline STE & Ste20 & SLK & 1 & $\begin{array}{l}\text { All } \\
\text { metazoans }\end{array}$ & C04A11.3 & & $\begin{array}{l}\text { Subfamily of } \\
\text { MAP4K kinases }\end{array}$ \\
\hline STE & Ste20 & STLK & 2 & $\begin{array}{l}\text { All } \\
\text { metazoans }\end{array}$ & $\begin{array}{l}\text { C03B1.5, } \\
\text { Y52D3.1 }\end{array}$ & & $\begin{array}{l}\text { Subfamily of } \\
\text { MAP4K kinases }\end{array}$ \\
\hline STE & Ste20 & TAO & 1 & $\begin{array}{l}\text { All } \\
\text { metazoans }\end{array}$ & T17E9.1 & & $\begin{array}{l}\text { Subfamily of } \\
\text { MAP4K kinases }\end{array}$ \\
\hline STE & Ste20 & YSK & 1 & $\begin{array}{l}\text { Metazoans, } \\
\text { fungi }\end{array}$ & T19A5.2 & & $\begin{array}{l}\text { Subfamily of } \\
\text { MAP4K kinases }\end{array}$ \\
\hline STE & Ste7 & & 10 & All kinomes & $\begin{array}{l}\text { jkk-1, mek-1, } \\
\text { mek-2, sek-1, } \\
\text { mkk-4,ZC449.6, } \\
\text { VZC374L.1, } \\
\text { E02D9.1a, } \\
\text { F35C8.2, } \\
\text { F35C8.1 }\end{array}$ & $\begin{array}{l}\text { RTKRas/ MAP } \\
\text { kinase signaling }\end{array}$ & $\begin{array}{l}\text { MAP kinase } \\
\text { kinase }\end{array}$ \\
\hline TK & Unique & & 7 & $\begin{array}{l}\text { All } \\
\text { metazoans }\end{array}$ & $\begin{array}{l}\text { C16D9.2, } \\
\text { Y38H6C.20, } \\
\text { F40A3.5, } \\
\text { F59F5.3, R151.4, } \\
\text { C34F11.5, } \\
\text { T22B11.3 }\end{array}$ & & \\
\hline TK & Abl & & 1 & All & $a b l-1$ & & Abelseon \\
\hline
\end{tabular}




\begin{tabular}{|c|c|c|c|c|c|c|c|}
\hline Group & Family & Subfamily & \begin{tabular}{|l} 
\# Kinases \\
(domains)
\end{tabular} & Distribution & Names & \begin{tabular}{|l|} 
Other \\
Wormbook \\
entries
\end{tabular} & $\begin{array}{l}\text { Name/ function } \\
\text { overview }\end{array}$ \\
\hline & & & & metazoans & & & $\begin{array}{l}\text { leukemia virus } \\
\text { homolog }\end{array}$ \\
\hline TK & Ack & & 2 & $\begin{array}{l}\text { All } \\
\text { metazoans }\end{array}$ & ark-1, kin-25 & & \\
\hline TK & Csk & & 1 & $\begin{array}{l}\text { All } \\
\text { metazoans }\end{array}$ & Y48G1C.2 & & \\
\hline TK & Fer & & 38 & $\begin{array}{l}\text { All } \\
\text { metazoans }\end{array}$ & $\begin{array}{l}\text { frk-1, spe-8, } \\
\text { kin-5, kin-14, } \\
\text { kin-21, kin-24, } \\
\text { kin-26, kin-28, } \\
\text { aSWK454, } \\
\text { Y43C5B.2, } \\
\text { Y116A8C.24, } \\
\text { K09B11.5, } \\
\text { Y52D5A.2, } \\
\text { Y69E1A.3, } \\
\text { T25B9.5, } \\
\text { M176.9, } \\
\text { ZC581.7, } \\
\text { F59A3.8, } \\
\text { R05H5.4, } \\
\text { W01B6.5, } \\
\text { T08G5.2, } \\
\text { F57B9.8, } \\
\text { T21G5.1, } \\
\text { C25A8.5, } \\
\text { T06C10.3, } \\
\text { F22B3.8, } \\
\text { F01D4.3, } \\
\text { W03F8.2, } \\
\text { ZK622.1, } \\
\text { R11E3.1, } \\
\text { T25B9.4, } \\
\text { ZK593.9, } \\
\text { F26E4.5, } \\
\text { W03A5.1, } \\
\text { C35E7.10, } \\
\text { C55C3.4, } \\
\text { C18H7.4, } \\
\text { F23C8.7 }\end{array}$ & & \\
\hline TK & Src & & 3 & \begin{tabular}{|l|} 
All \\
metazoans
\end{tabular} & $\begin{array}{l}s r c-1, s r c-2, \\
\text { Y47G6A.5a }\end{array}$ & & \begin{tabular}{|l|} 
Non-receptor \\
tyrosine kinase
\end{tabular} \\
\hline TKL & IRAK & & 1 & $\begin{array}{l}\text { All } \\
\text { metazoans }\end{array}$ & K09B11.1 & & $\begin{array}{l}\text { IL-1 receptor } \\
\text { associated kinase }\end{array}$ \\
\hline TKL & LRRK & & 1 & $\begin{array}{l}\text { Metazoans, } \\
\text { Dictyos- } \\
\text { telium }\end{array}$ & $\mathrm{T} 27 \mathrm{C} 10.5$ & & $\begin{array}{l}\text { Leucine rich } \\
\text { repeat kinase }\end{array}$ \\
\hline TKL & MLK & HH498 & 1 & $\begin{array}{l}\text { Nematodes, } \\
\text { vertebrates, } \\
\text { Dictyos- } \\
\text { telium }\end{array}$ & C24A1.3 & & Uncharacterized \\
\hline TKL & MLK & ILK & 1 & All & C29F9.7 & & Integrin linked \\
\hline
\end{tabular}




\begin{tabular}{|c|c|c|c|c|c|c|c|}
\hline Group & Family & Subfamily & $\begin{array}{l}\text { \# Kinases } \\
\text { (domains) }\end{array}$ & Distribution & Names & $\begin{array}{l}\text { Other } \\
\text { Wormbook } \\
\text { entries }\end{array}$ & $\begin{array}{l}\text { Name/ function } \\
\text { overview }\end{array}$ \\
\hline & & & & metazoans & & & kinase \\
\hline TKL & MLK & LZK & 1 & $\begin{array}{l}\text { All } \\
\text { metazoans }\end{array}$ & F33E2.2 & & \\
\hline TKL & MLK & MLK & 2 & $\begin{array}{l}\text { Metazoans, } \\
\text { Dictyos- } \\
\text { telium }\end{array}$ & $\begin{array}{l}\text { Y58A7A.f, } \\
\text { R13F6.7 }\end{array}$ & & $\begin{array}{l}\text { Mixed lineage } \\
\text { kinase }\end{array}$ \\
\hline TKL & MLK & TAK1 & 2 & $\begin{array}{l}\text { All } \\
\text { metazoans }\end{array}$ & $\begin{array}{l}\text { F52F12.3, } \\
\text { Y105C5.y }\end{array}$ & & \\
\hline TKL & RAF & & 3 & \begin{tabular}{|l|} 
All \\
metazoans
\end{tabular} & $\begin{array}{l}\text { raf-1, pex-1, } \\
\text { ksr-1 }\end{array}$ & $\begin{array}{l}\text { RTKRas/ MAP } \\
\text { kinase signaling }\end{array}$ & $\begin{array}{l}\text { Ras-MAPK } \\
\text { signaling }\end{array}$ \\
\hline TKL & STKR & Type1 & 2 & \begin{tabular}{|l|} 
All \\
metazoans
\end{tabular} & sma-6, daf-1 & $\begin{array}{l}\text { TGF- } \beta \\
\text { signaling }\end{array}$ & $\begin{array}{l}\mathrm{TGFb} \text { and related } \\
\text { receptors }\end{array}$ \\
\hline TKL & STKR & Type2 & 1 & \begin{tabular}{|l} 
All \\
metazoans
\end{tabular} & $d a f-4$ & \begin{tabular}{|l|} 
TGF- $\beta$ \\
signaling
\end{tabular} & $\begin{array}{l}\text { TGFb and related } \\
\text { receptors }\end{array}$ \\
\hline TK-RTK & Alk & & 1 & \begin{tabular}{|l|} 
All \\
metazoans
\end{tabular} & $s c d-2$ & & \\
\hline TK-RTK & DDR & & 2 & \begin{tabular}{|l} 
All \\
metazoans
\end{tabular} & $\begin{array}{l}\text { F11D5.3, } \\
\text { C25F6.4 }\end{array}$ & & $\begin{array}{l}\text { Discoidin domain } \\
\text { receptor. }\end{array}$ \\
\hline TK-RTK & EGFR & & 1 & \begin{tabular}{|l|} 
All \\
metazoans
\end{tabular} & let-23 & $\begin{array}{l}\text { RTKRas/ MAP } \\
\text { kinase signaling }\end{array}$ & $\begin{array}{l}\text { Growth factor } \\
\text { (EGF) receptor }\end{array}$ \\
\hline TK-RTK & Eph & & 1 & \begin{tabular}{|l|} 
All \\
metazoans
\end{tabular} & $v a b-1$ & & Ephrin receptor \\
\hline TK-RTK & Fak & & 1 & \begin{tabular}{|l|} 
All \\
metazoans
\end{tabular} & kin-32 & & $\begin{array}{l}\text { Focal adhesion } \\
\text { kinase }\end{array}$ \\
\hline TK-RTK & FGFR & & 1 & \begin{tabular}{|l} 
All \\
metazoans
\end{tabular} & egl-15 & $\begin{array}{l}\text { RTKRas/MAP } \\
\text { kinase signaling }\end{array}$ & $\begin{array}{l}\text { Growth factor } \\
\text { FGF) receptor }\end{array}$ \\
\hline TK-RTK & InsR & & 1 & \begin{tabular}{|l|} 
All \\
metazoans
\end{tabular} & $d a f-2$ & & Insulin receptor \\
\hline TK-RTK & KIN-16 & & $15(16)$ & Nematodes & $\begin{array}{l}\text { old-1, old-2, } \\
\text { ver-1, R09D1.13, } \\
\text { kin-23, T17A3.8, } \\
\text { T01G5.1, } \\
\text { C08H9.8, } \\
\text { F59F3.1, } \\
\text { M176.7, } \\
\text { F59F3.5, } \\
\text { M176.6, kin-30, } \\
\text { R09D1.12, } \\
\text { Y50D4B.6 } \\
\end{array}$ & & Uncharacterized \\
\hline TK-RTK & KIN-9 & & 5 & Nematodes & $\begin{array}{l}\text { F09G2.1, } \\
\text { F09A5.2, } \\
\text { C24G6.2, } \\
\text { F08F1.1, } \\
\text { B0252.1 }\end{array}$ & & Uncharacterized \\
\hline TK-RTK & Met & & 2 & $\begin{array}{l}\text { Nematodes } \\
\text { and } \\
\text { vertebrates }\end{array}$ & $\begin{array}{l}\text { F11E6.8, } \\
\text { T14E8.1 }\end{array}$ & & $\begin{array}{l}\text { Growth factor } \\
\text { (HGF/SF) } \\
\text { receptor }\end{array}$ \\
\hline TK-RTK & Ror & & 1 & All & cam-1 & & Receptor tyrosine \\
\hline
\end{tabular}




\begin{tabular}{|l|l|l|l|l|l|l|l|}
\hline Group & Family & Subfamily & $\begin{array}{l}\text { \# Kinases } \\
\text { (domains) }\end{array}$ & Distribution & Names & $\begin{array}{l}\text { Other } \\
\text { Wormbook } \\
\text { entries }\end{array}$ & $\begin{array}{l}\text { Name/ function } \\
\text { overview }\end{array}$ \\
\hline TK-RTK & Ryk & & 1 & $\begin{array}{l}\text { All } \\
\text { metazoans }\end{array}$ & C16B8.1 & & kinase \\
\hline TK-RTK & Trk & & 1 & $\begin{array}{l}\text { Nematodes } \\
\text { and } \\
\text { vertebrates }\end{array}$ & D1073.1 & & $\begin{array}{l}\text { Neurotropin } \\
\text { receptor }\end{array}$ \\
\hline TOTAL & & & $438(447)$ & & & & \\
\hline
\end{tabular}

All WormBook content, except where otherwise noted, is licensed under a Creative SOMEREIGHIS RESERVED Commons Attribution License 